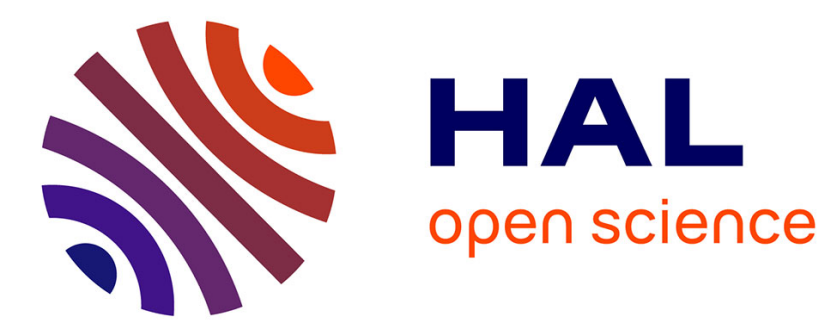

\title{
VECTOR-QUATERNION DESCRIPTION OF MISORIENTATIONS
}

\author{
V. Gertsman
}

\section{To cite this version:}

V. Gertsman. VECTOR-QUATERNION DESCRIPTION OF MISORIENTATIONS. Journal de Physique Colloques, 1990, 51 (C1), pp.C1-145-C1-150. 10.1051/jphyscol:1990121 . jpa-00230279

\section{HAL Id: jpa-00230279 https://hal.science/jpa-00230279}

Submitted on 1 Jan 1990

HAL is a multi-disciplinary open access archive for the deposit and dissemination of scientific research documents, whether they are published or not. The documents may come from teaching and research institutions in France or abroad, or from public or private research centers.
L'archive ouverte pluridisciplinaire HAL, est destinée au dépôt et à la diffusion de documents scientifiques de niveau recherche, publiés ou non, émanant des établissements d'enseignement et de recherche français ou étrangers, des laboratoires publics ou privés. 


\title{
VECTOR-QUATERUION DESCRIPTION OF MISORIENTATIONS
}

\author{
V.YU. GERTSMAN \\ Institute of Metals Superplasticity Problems, URSS Academy of Sciences, \\ ul. Khalturina 39, Ufa 450001, U.R.S.S.
}

\begin{abstract}
A unified formal description of misorientations of crystals of any type of symmetry is suggested. A simple algorithm for determining coincidence misorientations for cubic, hexagonal and tetragonal systems is described.
\end{abstract}

It is known that for two misoriented crystals a common sublattice may be introduced, i.e. coincidence site lattice (CSL). The concept of CSL underlies modern geometrical theory of interfaces. Misorientations which result in CSL's with a high degree of coincidence ${ }^{(1)}$ are denominated as special misorientations.

Up to now, for calculations of special misorientations, a separate algorithm had to be developed for each lattice. The tables of special misorientations for cubic system [1] and some hexagonal lattices [2] have been calculated basing on the properties of the elements of rotation matrix. In [3] special misorientations of cubic crystals have been calculated on the basis of quaternion description, a similar method was suggested in [4,5] for hexagonal crystals. Nowadays only tables of special rotations for the most wide-spread high symmetry lattices are available which can not obviously cover all possible cases, e.g. the whole variety of axial ratios for non-cubic lattices. For many applications it would be useful to have a general and simplified formalized algorithm to calculate them.

This paper suggests an economical method for description of misorientations of crystals of any type of symmetry and a simple algorithm for finding special misorientations of cubic, hexagonal and tetragonal crystals. This algorithm is similar to those used in [3-5] and actually generalizes them.

of the multiple methods of mathematical description of misorientation the following two are mostly spread: in the form of an angle/axis pair and in the form of a rotation matrix (see [1]). But the most economical way is to represent rotation in the form of three-dimensional Gibbs vector $G$ since in a general case only three independent parameters are needed to present misorientation.

Thus we assume that misorientation is given by vector

$$
G=[p-q-r] \text {. }
$$

In this case the rotation axis runs in the direction common both the neibouring crystals and the misorientation angle for lattices of length of the $G$ vector

$$
\tan (\theta / 2)=\operatorname{moc} g \text {. }
$$
is given by the

(1) degree of coincidence is described by index $\sum$ - the reciprocal of the density of concidence sites 
Then, for cubic system

$$
\tan ^{2}(\theta / 2)=p^{2}+q^{2}+r^{2} \text {. }
$$

for hexagonal system

$$
\tan ^{2}(\theta / 2)=p^{2}+q^{2}-p q+(c / a)^{2} x^{2},
$$

for tetragonal system

$$
\tan ^{2}(\theta / 2)=p^{2}+q^{2}+(c / a)^{2} r^{2},
$$

where $c / \boldsymbol{a}$ is an axial ratio for hexagonal and tetragonal lattices.

For the CSL to exist it is necessary and sufficient for the rotation axis to have rational indices and for the rotation angle to satisfy the following requirement [7]:

$$
\tan ^{2}(0 / 2)=x / Y \text {, }
$$

where $X$ and $Y$ are integers, and

$$
X+X=i \sum
$$

where $I$ is a certain integer.

It could be shown then that for special misorientations

$$
\mathrm{G}=\boldsymbol{a} \mathbf{\mathrm { C }} \mathrm{k}, \mathrm{I}, \mathrm{mJ} / \mathrm{m} \text {. }
$$

where $\mathbf{k}, \mathbf{l}, \mathbf{m}, \mathbf{n}$ - are integers without common divisor.

$\infty=I$ for cubic system, $\equiv=a / c \sqrt{3}$ for hexagonal system, $\equiv=a / c$ : for tetragonal system.

Thus, any special misorientation is determined by four coprime integers quaternion $(\mathbf{k}, \mathbf{I}, \mathbf{m}, \boldsymbol{n})$ and so, according to $(3)$, the reciprocal dencity of coincidence sites may be found in the following way:

For cubic system

$$
\sum=\xi\left(x^{2}+1^{2}+m^{2}+n^{2}\right) \text {. }
$$

where $\xi=1$, when only one number out of $k, 1, m, n$ is either even or odd and the other three are of an opposite parity; $\xi=1 / 2$ when two numbers are even and two odd; $\xi=1 / 4$ when all numbers of quaternion are odd.

In hexagonal and tetragonal systems for all rotations, except misorientations around the [001] axis, CSL's do exist, if $(c / a)^{2}=\mu / \nu$, where $\mu$ and $\downarrow$ are integers.

For hexagonal system

$$
\Sigma=\xi\left[\nu\left(k^{2}+1^{2}-k 1\right)+\mu\left(m^{2}+3 n^{2}\right)\right]
$$

In ref.[5] it was found, that

$$
\xi=1 / \alpha \beta \gamma \delta \text {, }
$$

where $\alpha$ is the greatest common divisor of $12, k^{2}+11^{2}-1 \times 1$. $m^{2}+3 n^{2}$

$\beta$ is the common divisor of $\mu, 3 k, 31 . \quad \beta^{2}$ being a divisor of $\left(k^{2}+1^{2}-k 1\right) / ;$ is the greatest common divisor of $4, \nu,\left(m^{2}+3 n^{2}\right) / \alpha$; $\delta$ is the common divisor of $\nu, \gamma$, m. n. $\delta^{2}$ being a divisor of $\left(m^{2}+3 n^{2}\right) / \alpha \gamma$.

For tetragonal system

$$
\sum_{\Sigma}=\xi\left[\nu\left(k^{2}+1^{2}\right)+\mu\left(m^{2}+n^{2}\right)\right]
$$

where $\xi=1, \alpha \beta \gamma$,

$\alpha=2$ when $\mathbf{k}^{2}+1^{2}$ and $\mathrm{m}^{2}+\mathrm{m}^{2}$ are even integers, otherwise $\alpha=1$.

$\beta$ is the greatest common divisor of $\mu, 2 k, 21,\left(k^{2}+12\right) / \alpha$; $\gamma$ is the greatest common divisor of $\nu, 2 m, 2 n,\left(m^{2}+n^{2}\right) / \alpha$. 
Due to the lattice symmetry the same misorientation may be described by different equivalent ways. These equivalent misorientations are easily found in quaternion form.

The following quaternion descriptions are equivalent for cubic system:

$$
\begin{aligned}
& (k, 1, m, n) \\
& (k+1, k-1, m+n, m-n) \\
& (k+m, k-n, I+n-1-n) \\
& (k+n, k-n, 1+m-1-m) \\
& (k+1+m+n, k+1-m-n, k-1-m+n, k-1+m-n) \\
& (k+1+m-n, k+1-m+n, k-1+m+n, k-1-m-n)
\end{aligned}
$$

Any permutations of elements within quaternion (as well as alterations of signs) are permitted.

Equivalent descriptions for hexagonal system:

$$
\begin{aligned}
& (\mathbf{k}, 1, \mathrm{~m}, \mathrm{n}) \\
& (2 k, 21, m+3 m-m-n) \\
& (2 k, 21, m-3 n, m+n) \\
& (2 k-1, k-21,3 n, m) \\
& (4 k-21,2 k-4 l \cdot 3 m+3 n, m-3 n) \\
& (4 k-21,2 k-41,3 m-3 n,+-3 n) \\
& (2 \mu m+2 \mu n-4 \mu n-\nu k+\nu 1-\nu k-\nu 1) \\
& \left(2 \mu m+2 \mu n, 4 \mu n, 2 \nu k-\nu_{1}-\nu_{1}\right) \\
& \left(2 \mu \mathrm{n}+2 \mu \mathrm{r}, 4 \mu \mathrm{n}, \nu_{k-2} \nu_{1}-\nu_{k}\right) \\
& \text { (4 } 4 \mu m-2 \mu m-6 \mu n-3 \nu k, \nu k-2 \nu 1) \\
& \text { (4 } \left.\mu^{\mu m}-2 \rho^{\mu m-6} \mu n-3 \nu 1.2 \nu k-\nu 1\right) \\
& \left(4 \mu \mathrm{m}, 2 \mu \mathrm{m}-6 \mu \mathrm{n}, 3 \nu \mathrm{k}-3 \nu 1, \nu_{k}+\nu 1\right)
\end{aligned}
$$

Equivalent descriptions for tetragonal system:

$$
\begin{aligned}
& (k, 1, m-n) \\
& (k+1, k-1, m+n-m-n) \\
& \left(\mu m-\mu n, \nu k-\nu_{1}\right) \\
& \left(\mu m+\mu r, \mu m-\mu n-\nu_{k}+\nu 1, \nu_{k}-\nu_{1}\right)
\end{aligned}
$$

For hexagonal system it is only possible to change position of the first and second quaternion coefficients, but for tetragonal system also of the third and forth. Obviously, coefficients of every quaternion (6) must be reduced to coprime form.

Now the algorithm of finding special misorientations can be easily described. Quaternion of integers $(k, 1, m, m)$ satisfying requirement (5) has to be found for the given $\sum$. This presents no difficulty using exhaustive search executed by computer. Then one finds an equivalent description using Eqs. (6) and determines misorientation axis and angle using Eqs. (4), (1). Description with minimal angle usually serves as the main one. The transition from quaternion to matrix description may be found in [6].

The multiplication law for misorientations given in the vector form is as follows:

$$
G_{1}+G_{2}=\left(S_{1}+S_{2}+G_{1} \times S_{2}\right) /\left(1-G_{1} G_{2}\right) \text {. }
$$

Hence, "the difference" of two misorientations, e.g. the deviation of $C$ misorientation from special $G_{0}$ :

$$
G-G_{0}=\left(S-G_{0}-G \times G_{0}\right) /\left(1+G G_{0}\right) \text {. }
$$


and in the expanded form:

$\cos (\Delta \theta / 2)=\frac{\left(1+p_{0}+q_{0}+r q_{0}\right)}{\left[\left(1+p^{2}+q^{2}+r^{2}\right)\left(1+p_{0}^{2} q_{0}^{2}+r_{0}^{2}\right]^{1 / 2}\right.}$

the "deviation-rotation" axis runs along the direction

Ep-potaro-ar.

$$
q-q_{0}-r_{o}+p_{o} r-r_{o}+p_{o}-p_{o} q u .
$$

The described algorithm was used to calculate special misorientations for tetragonal lattice with the ratio of $(\mathrm{c} / \mathrm{a})^{2}=2$. Many ordered alloys and intermetaliic compounds with the Llo structure have such a lattice, e.g. TiAl $(c / a)^{2}=2.04, \operatorname{PtCr}(c / a)^{2}=2.00, \operatorname{GaTi}(c / a)^{2}=2.00, \quad \operatorname{TiAg}(c / a)^{2}=1.98, \quad \mathrm{NaBi}$ $(c / a)^{2}=1.96$, PtCo $(c / a)^{2}=1.95, \quad$ CuAu $(c / a)^{2}=1.84$ and others. Since in a disordered state such a lattice has f.c.c. structure, it is usual to employ cubic coordinate system for it, though the Bravais lattice here is a basic centered tetragonal. That is why in the table the rotation axes are given both in tetragonal and cubic coordinate systems. Among the equivalent rotations solely smallest-angle descriptions were chosen. If one value corresponds to different non-equivalent misorientations, they are labelled $a, b, c$, etc. and are given in the increasing order of $\theta_{\text {min }}$ as generally accepted [3].

Comparison of the calculated table with those given in [1,3] indicates that many special misorientations for the given lattice coincide with corresponding misorientations for cubic lattices. Particulary, any tetragonal lattice misorientation around the [.001] axis is equivalent to cubic misorientations around $\langle 100\rangle$ axes. But there are also significant pecularities of special misorientations in tetragonal lattice. Thus e.g. misorientation $\sum_{5} 36.9^{\circ}\langle 100\rangle$ in cubic lattice splits into four in tetragonal lattice: $\sum 5 a, \quad \sum 5 b$, $\sum l 0 a$, and $\sum 10 b$ (see the table), since rotatiton axes for $\sum 5 a$ and $\sum 5 b$ are crystallographically non-equivalent here and the $\langle 100\rangle$ axis in tetragonal lattice is not the axis of symmetry of the 4-th order as is the corresponding $\langle 100\rangle$ axis in cube. CSL's with $\sum 5 b$ and $\sum 10$ differ in the following. In the $\sum 5 b$ CSL every fifth sjte coincides in every (110) plane as is the case also ir. the corresponding CSL $\sum 5$ in cubic lattice, but in CSL $\sum 10$ such a coincidence occurs in every second (110) plane while in the-others "anti-coincidence" takes place, i.e. coinciding are the sites occupied by atoms of various species. This "anti-coincidence" is a feature of all CSL's with even $\sum$, the structure of boundaries with such misorientations is sure to contain elements of anti-phase boundaries. For example, misorientation $\sum 2$ actually characterises the so-called C-domains.

\section{REFERENCES}

1. Grimmer, H., Bollmann, W., and Warrington, D.H., Acta Crysta11. A30 (1974) 197.

2. Warrington, D.H., J.Phys. C4 36 (1975) 87.

3. Mykura, H., In R.W. Balluffi (Ed.), "Grain Boundary Structure and Kinetics", ASM-Metal Park, Ohio (1980) 445.

4. Hagege, S. and Nouet, G., Scripta Metall. 19 (1985) 11.

5. Grimmer, H. and Warrington, D.H., Coincidence orientations of Grains in Hexagonal materials. EIR-Bericht No.593, Würenlingen (1986).

6. Korn, G.A. and Korn, T.M., Mathematical Handbook, McGraw-Hiil, N.V. et al.

7. Ranganathan, S., Acta Crysta11. 21 (1966) 197. 
TABLE OF CSI. MISORIENTATIONS UP TO $\sum=49$ FOR TETRAGONAL LATTICE WITH THE AXIAL RATIO $c / a=\sqrt{2}$

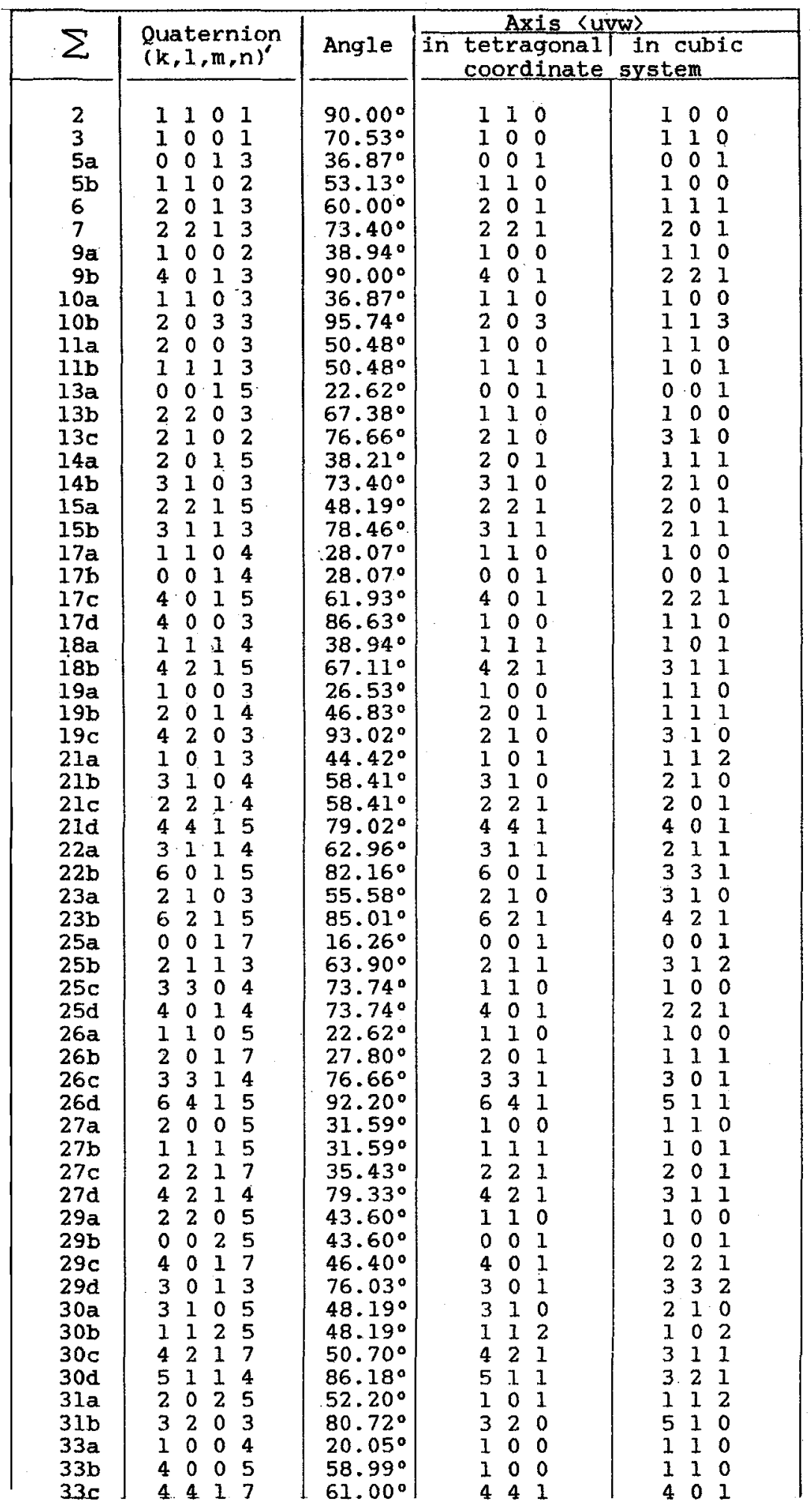


TABLE (continued)

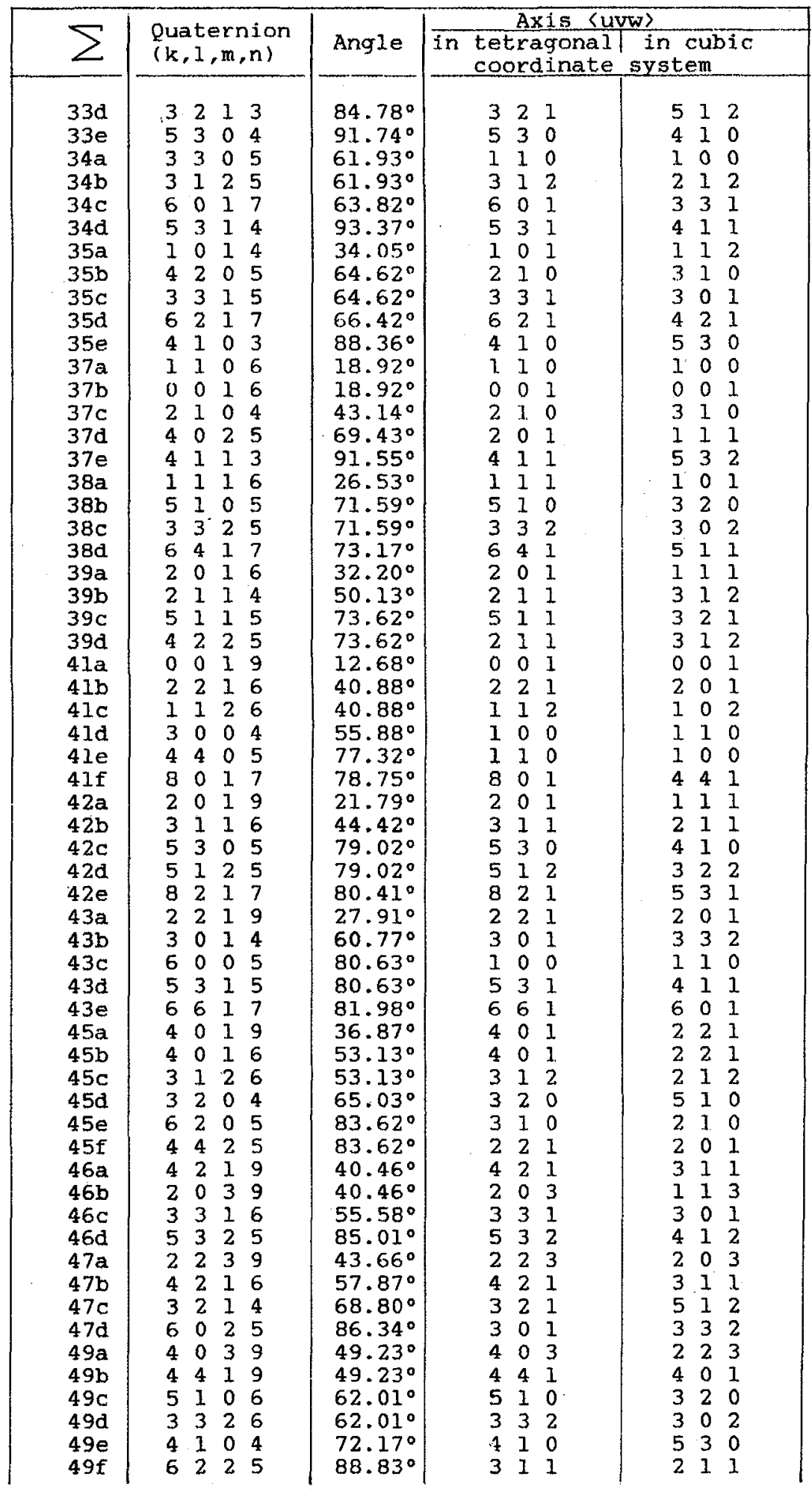

